\title{
Multiscale Modeling of Ceramic Matrix Composites
}

\author{
Brett A. Bednarcyk ${ }^{1}$, Subodh K. Mital ${ }^{2}$, Evan J. Pineda ${ }^{3}$, and Steven M. Arnold \\ NASA Glenn Research Center, Cleveland, OH, 44135, U.S.A.
}

\begin{abstract}
Results of multiscale modeling simulations of the nonlinear response of $\mathrm{SiC} / \mathrm{SiC}$ ceramic matrix composites are reported, wherein the microstructure of the ceramic matrix is captured. This micro scale architecture, which contains free Si material as well as the SiC ceramic, is responsible for residual stresses that play an important role in the subsequent thermo-mechanical behavior of the $\mathrm{SiC} / \mathrm{SiC}$ composite. Using the novel Multiscale Generalized Method of Cells recursive micromechanics theory, the microstructure of the matrix, as well as the microstructure of the composite (fiber and matrix) can be captured.
\end{abstract}

\section{Introduction}

$\mathrm{C}$ ERAMIC matrix composites (CMCs) provide excellent high-temperature capabilities with much lower mass compared to high-temperature superalloys. They are thus under development for aerospace applications such as entry, ascent, and cruise vehicles, leading edges, control surfaces, combustor liners, and gas turbine engine vanes and blades. Silicon carbide fiber/silicon carbide matrix $(\mathrm{SiC} / \mathrm{SiC})$ composites are particularly attractive for use in air-breathing gas turbine engines. Examples of three types of $\mathrm{SiC} / \mathrm{SiC}$ composites are shown in Figure 1. Woven melt infiltrated (MI) $\mathrm{SiC} / \mathrm{SiC}$ composites tend to have voids within the tows, but good matrix density between the tows. However, the presence of $\mathrm{Si}$ within the matrix limits their use temperatures to $1350{ }^{\circ} \mathrm{C}$. Woven chemical vapor infiltrated (CVI) $\mathrm{SiC} / \mathrm{SiC}$ composites have voids within the tows as well as large voids between the tows. These composites are $\mathrm{Si}$ free, allowing use up to $1500{ }^{\circ} \mathrm{C}$. With unidirectional and laminated $\mathrm{MI} \mathrm{SiC/SiC}$ composites, excellent matrix density can be achieved both within and between the tows with a simpler manufacturing. However, like woven MI SiC/SiC, unidirectional and laminated $\mathrm{MI} \mathrm{SiC/SiC}$ contain $\mathrm{Si}$ within the matrix, which limits use temperature. In all three types of $\mathrm{SiC} / \mathrm{SiC}$ composites, the fiber filaments are coated with $\mathrm{BN}$, which provides a very compliant interface to inhibit matrix cracks from entering the fibers. The focus of this study is the unidirectional MI SiC/SiC material.

Example tensile response curves for laminated and unidirectional $\mathrm{MI} \mathrm{SiC/SiC}$, as a function of fiber volume fraction, are shown in Figure 2. It is clear that there is a distinctive knee in each of the stress-strain curves, which is associated with cracking of the matrix. Obviously, residual stresses from the manufacturing of the composite present in the matrix will have an impact on the stress at which this knee occurs. It is thus important to capture these

\footnotetext{
${ }^{1}$ Materials Research Engineer, 21000 Brookpark Road, MS 49/7, AIAA Associate Fellow.

${ }^{2}$ University of Toledo, Senior Researcher, 21000 Brookpark Road, MS 49/7.

${ }^{3}$ Aerospace Research Engineer, 21000 Brookpark Road, MS 49/7, AIAA Member.

${ }^{4}$ Aerospace Research Engineer, 21000 Brookpark Road, MS 49/7, AIAA Member.
} 
residual stresses when predicting the response of the composite. Herein, the Multiscale Generalized Method of Cells (MSGMC) recursive micromechanics model (Liu et al., 2011, 2013; Aboudi et al., 2013) is used to predict these residual stresses, and the effect of these residual stresses on the subsequent nonlinear behavior of the unidirectional $\mathrm{MI} \mathrm{SiC/SiC} \mathrm{composite.}$

(a)
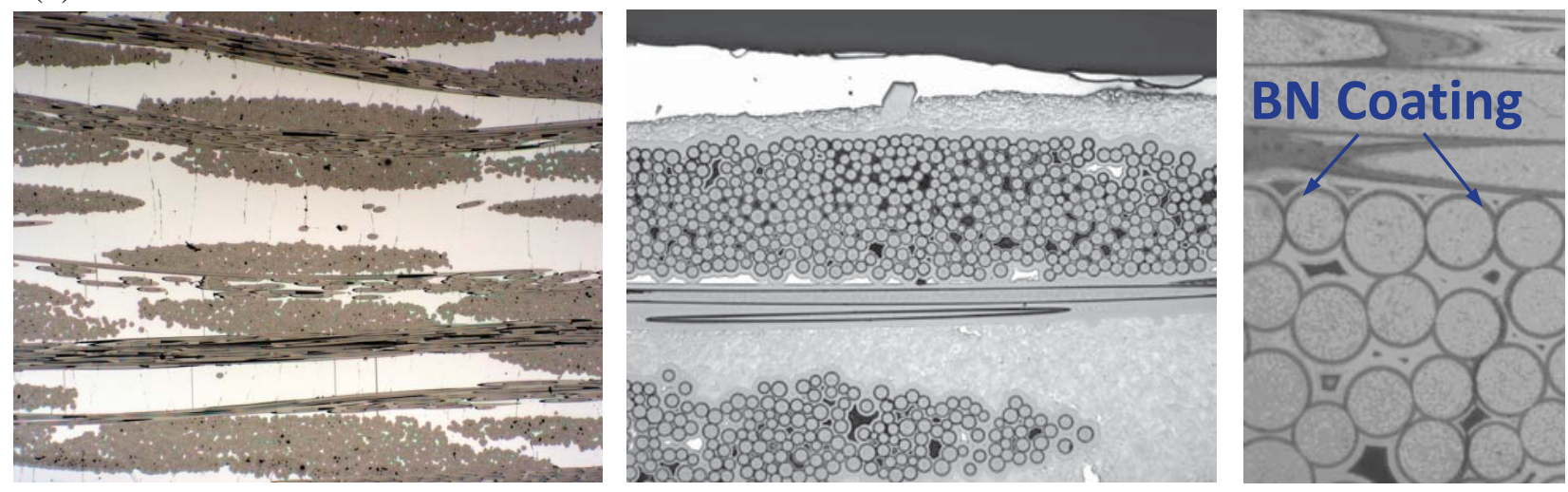

(b)
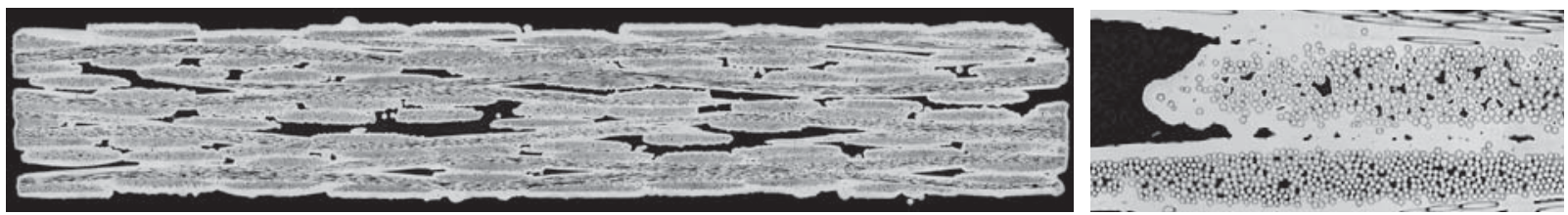

(c)
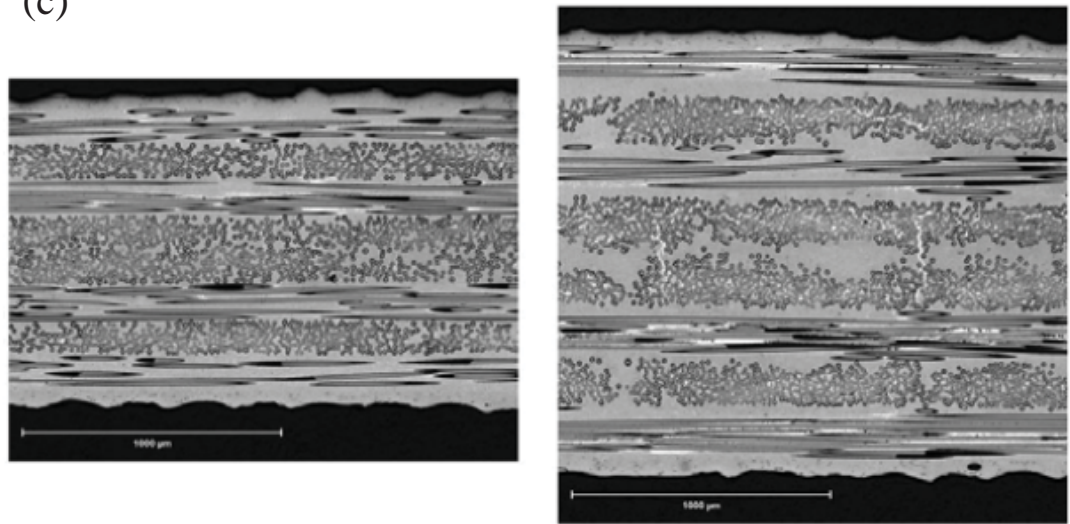

Figure 1. Three types of $\mathrm{SiC} / \mathrm{SiC}$ composites (a) Woven melt infiltrated (MI) $\mathrm{SiC} / \mathrm{SiC}$. (b) Woven chemical vapor infiltration (CVI) SiC/SiC. (c) Unidirectional or laminated $\mathrm{MI} \mathrm{SiC/SiC}$. 


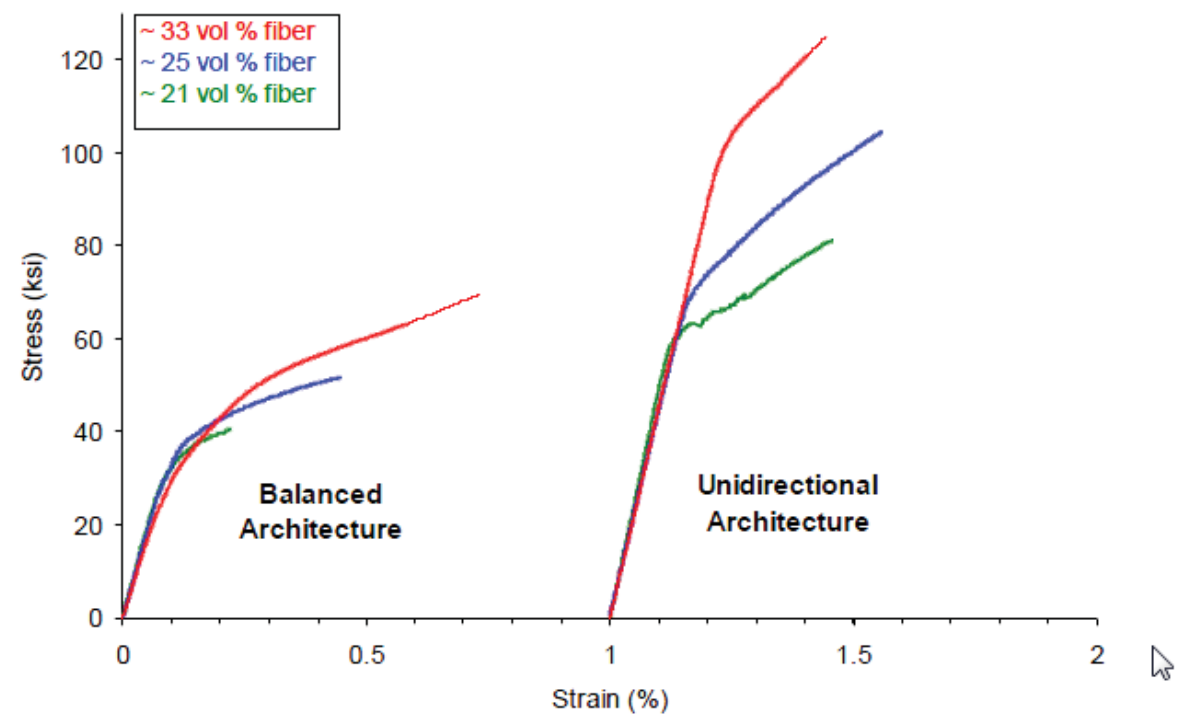

Figure 2. Example tensile response of laminated and unidirectional MI SiC/SiC (Dunn, 2010).

\section{Micromechanics Model}

The MSGMC micromechanics model (Liu et al., 2011, 2013) is based on the well-known Generalized Method of Cells micromechanics theory (Paley and Aboudi, 1992; Aboudi et al., 2013) wherein a recursive capability has been incorporated. As such, as shown in Figure 3, the subcells within the global GMC repeating unit cell (RUC), rather than containing monolithic materials, may be occupied by another RUC. The effective nonlinear behavior of the subcell within the global RUC is thus determined from the homogenization of the lower scale RUC, with nonlinear constitutive models operating within the lower scale subcells. The lower scale subcells can also be occupied by RUCs, so an arbitrary number of scales can be modeled with the MSGMC approach.

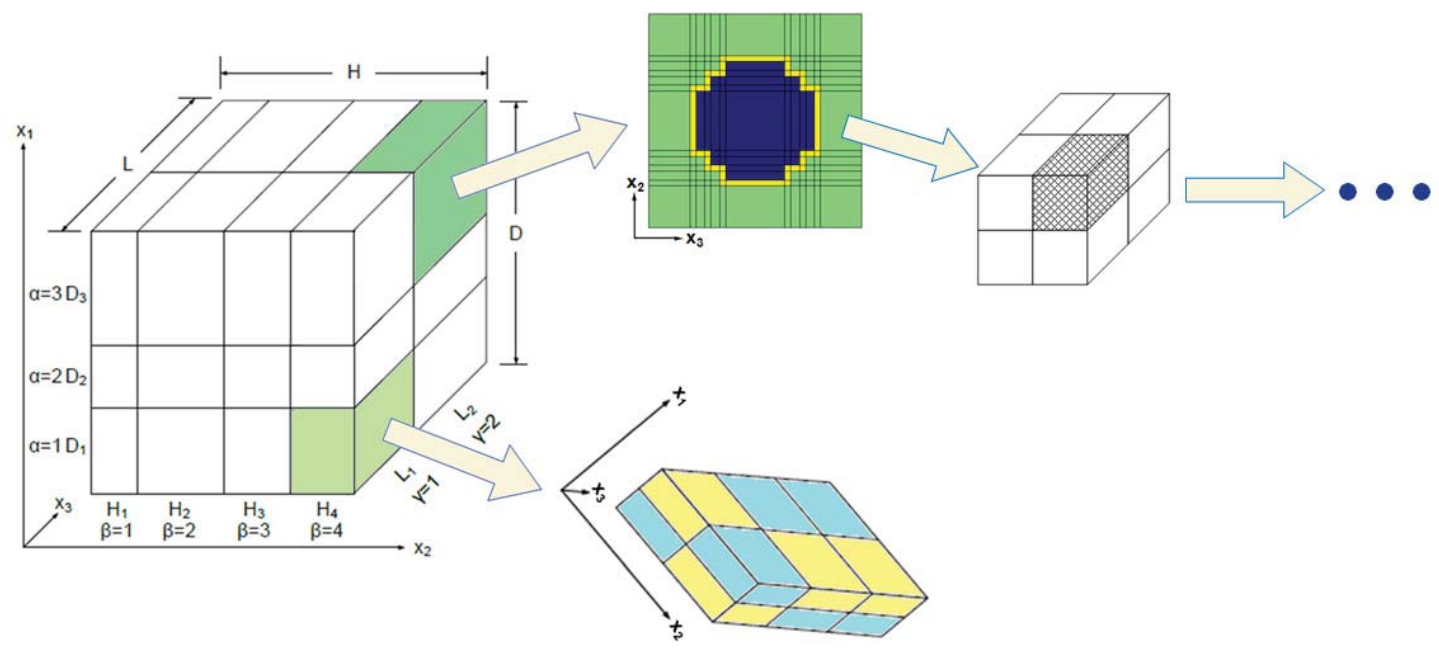

Figure 3. Schematic of the MSGMC recursive micromechanics model.

3

American Institute of Aeronautics and Astronautics 


\section{Results and Discussion}

Figure 4 shows the global and local RUCs used to model the unidirectional MI SiC/SiC composite. The doubly periodic global RUC consists of the SiC fiber, surrounded by the compliant BN interface, and an effective matrix, which contains both $\mathrm{SiC}$ and $\mathrm{Si}$, as represented by the local RUCs. Two local triply periodic local RUCs were considered, both with the same volume fractions of $\mathrm{SiC}$ and $\mathrm{Si}$, one with $\mathrm{Si}$ surrounded by $\mathrm{SiC}$ and one with $\mathrm{SiC}$ surrounded by $\mathrm{Si}$.

To capture the residual stresses from manufacturing of the composite, it is important to model the timedependent creep/relaxation response of the constituents. Figure 5 shows the assumed power law creep response of the composite constituents at three elevated temperatures denoted by $T_{1}, T_{2}$, and $T_{3}$, with $T_{1}>T_{2}>T_{3}$. Comparing Figure $5 \mathrm{a}, \mathrm{b}$, and c, it is clear that the $\mathrm{Si}$ creeps much more than the $\mathrm{SiC}$ matrix material, which creeps much more than the $\mathrm{SiC}$ fiber. The creep of all three constituents shuts down at lower temperatures.

The predicted longitudinal (fiber-direction) residual stresses in the composite due to manufacturing are plotted in Figure 6 for the case with the matrix represented as Si surrounded by SiC and the case with the matrix represented as $\mathrm{SiC}$ surrounded by $\mathrm{Si}$. In both cases, the fiber is in residual tension, while the effective matrix (consisting of $\mathrm{Si}$ and $\mathrm{SiC}$ ) is in residual compression. The case with $\mathrm{SiC}$ surrounded by $\mathrm{Si}$ predicts higher magnitude residual stresses. At the local scale within the effective matrix, the case with $\mathrm{Si}$ surrounded by $\mathrm{SiC}$ predicts that most of the $\mathrm{SiC}$ is in residual compression, but some $\mathrm{SiC}$ is in residual tension. In contrast, for the case with $\mathrm{SiC}$ surrounded by $\mathrm{Si}$, all of the $\mathrm{SiC}$ is predicted to be in residual compression (with a small amount of $\mathrm{Si}$ in residual tension).

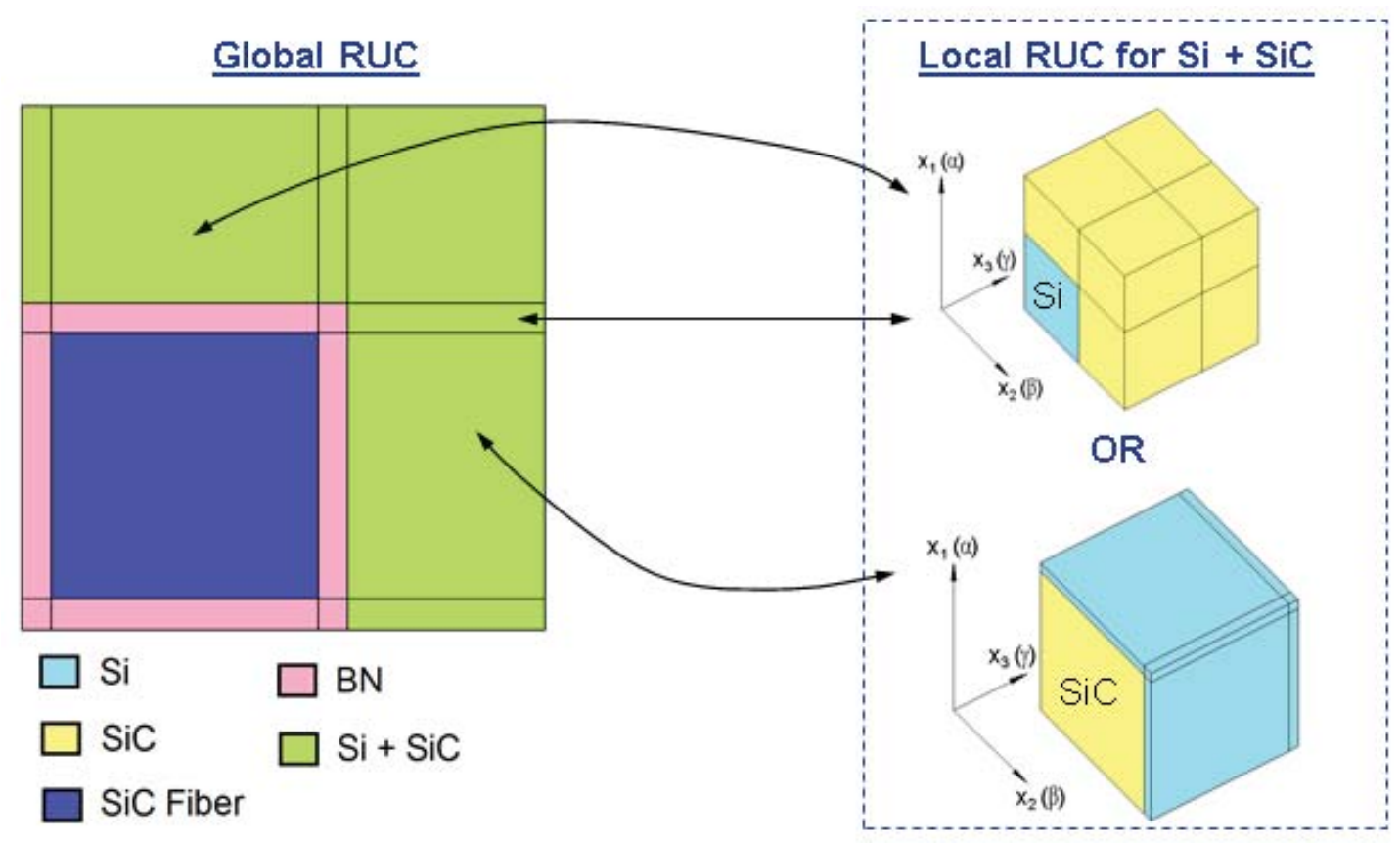

Figure 4. MSGMC RUCs representing the unidirectional MI SiC/SiC composite. 
(a)

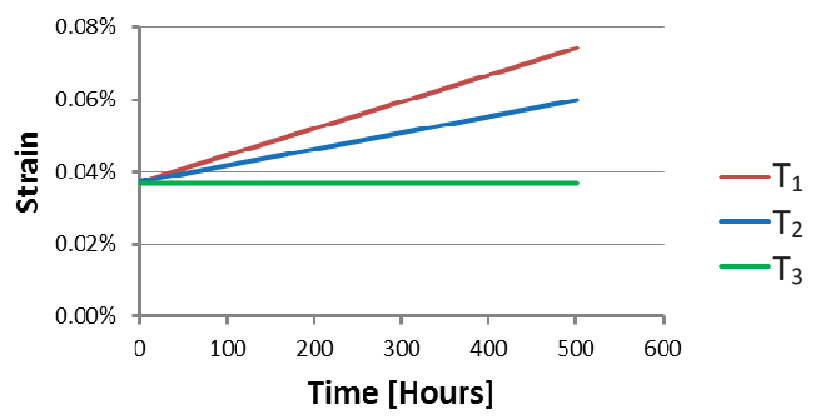

(b)

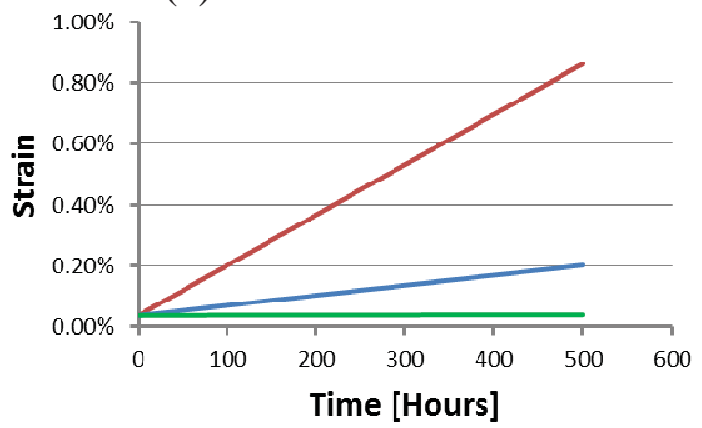

(c)

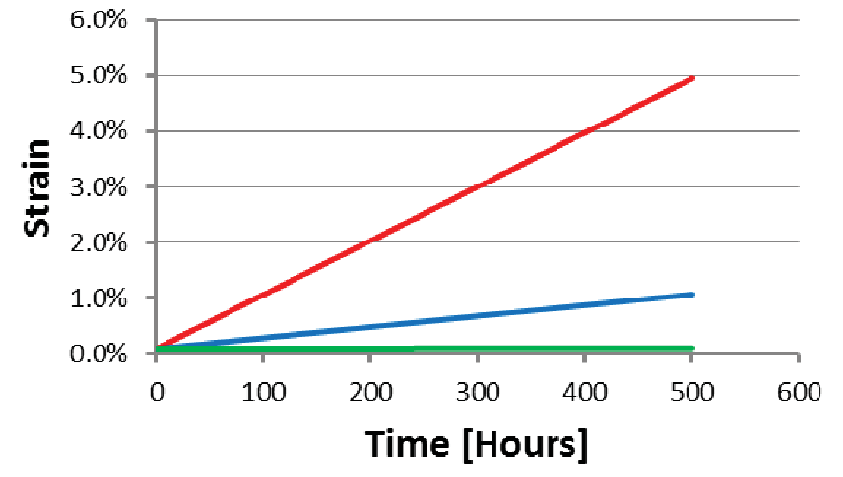

Figure 5. Employed creep response of the constituents of the unidirectional $\mathrm{MI} \mathrm{SiC} / \mathrm{SiC}$ composite for $\mathrm{T}_{1}>\mathrm{T}_{2}$ $>\mathrm{T}$. (a) SiC Fiber, (b) SiC material within matrix, (c) Si material within matrix. Note the vastly different $\mathrm{y}$ axis scales.
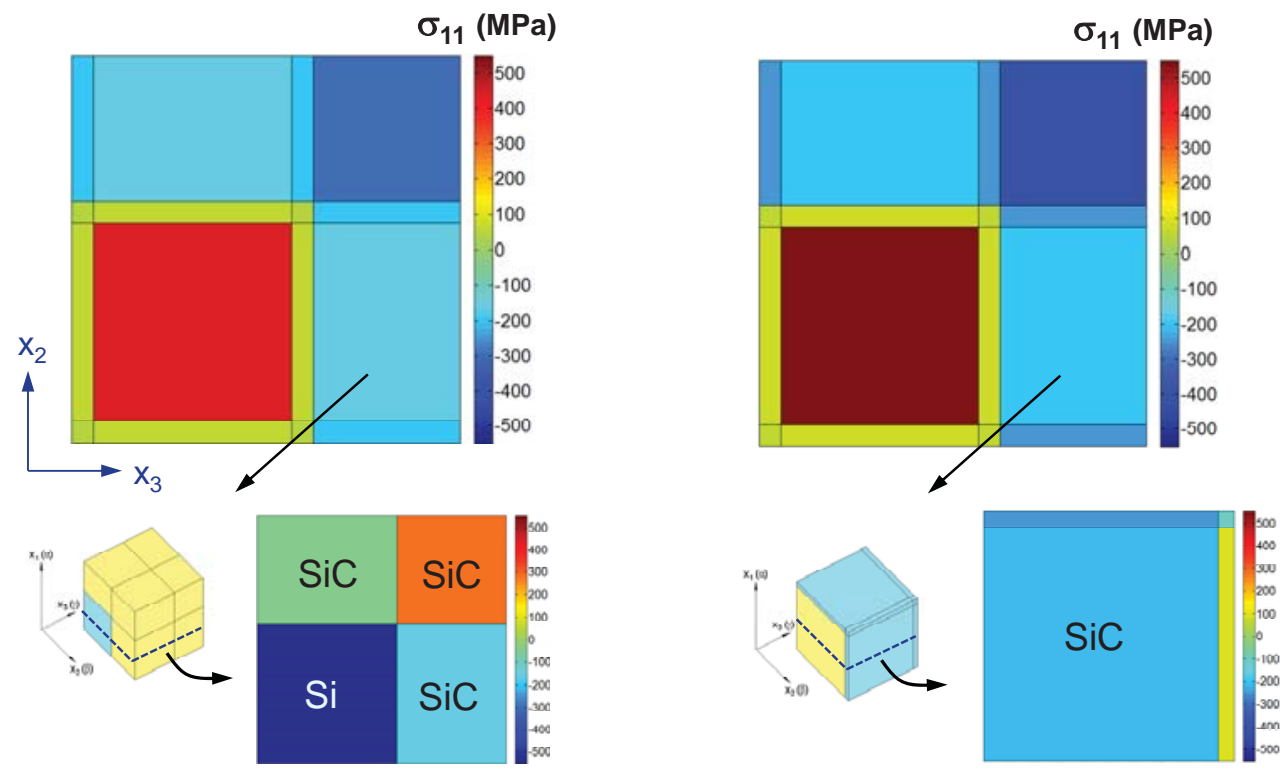

Figure 6. Multiscale longitudinal residual stresses predicted by MSGMC for the unidirectional MI SiC/SiC composite. 
The impact of the residual stresses on the room temperature tensile response of the composite is shown in Figure 7, for the case of the matrix represented by SiC surrounded by Si. Here a bilinear progressive damage model was employed for the $\mathrm{SiC}$ material within the matrix and a max stress failure criterion was used for the fiber. As shown, due to the residual compression in the matrix and residual tension in the fiber, the predicted knee in the stress strain curve is raised significantly (proportional limit stress, PLS, increases), while the predicted strain to failure $\left(\varepsilon_{\mathrm{f}}\right)$, decreases. If the PLS is used as a design criterion for the composite material, then clearly the residual stresses are very beneficial.

Figure 8 shows the predicted effect of heat treatment on the composite room temperature response. Heat treatment at the lower temperature $T_{3}$ (see Figure 5), even for a very long time ( $\mathrm{t}_{1}$ ), allows only a small amount of the residual stress to relax, and thus only changes the tensile response slightly. However, heat treatment at the higher $\mathrm{T}_{1}$ for a much shorter time $\left(\mathrm{t}_{2}=\mathrm{t}_{1} / 10\right)$ relaxes a great deal of the residual stress, and the composite tensile response is much closer to the predicted response with no residual stresses.

Figure 9 shows the impact of heat treatment at the higher temperature $\left(T_{1}\right)$ for the shorter time $\left(t_{2}\right)$ on the predicted creep response of the composite at the higher temperature $\left(T_{1}\right)$. The applied stress level is $200 \mathrm{MPa}$, which is below the predicted PLS of the composite. The effect is noticeable, but not large as the composite does not creep very much in the longitudinal direction (due to the presence of the fiber) and by heating up to $\mathrm{T}_{1}$ prior to applying the simulated creep loading, some of the residual stresses are eliminated even for the case without heat treatment.

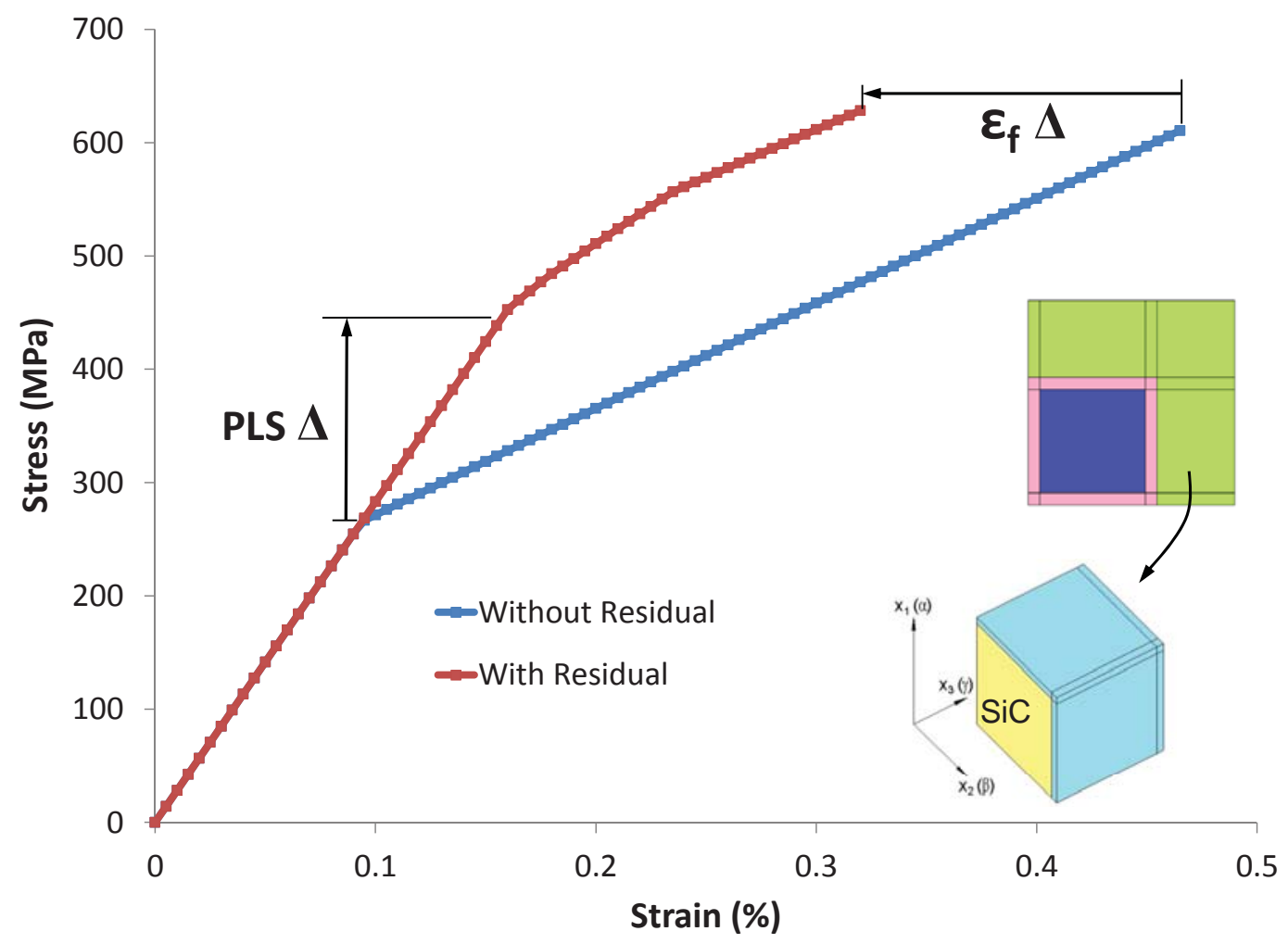

Figure 7. Predicted room temperature longitudinal tensile response of the unidirectional $\mathrm{MI} \mathrm{SiC/SiC}$ composite with and without residual stresses included.

6

American Institute of Aeronautics and Astronautics 


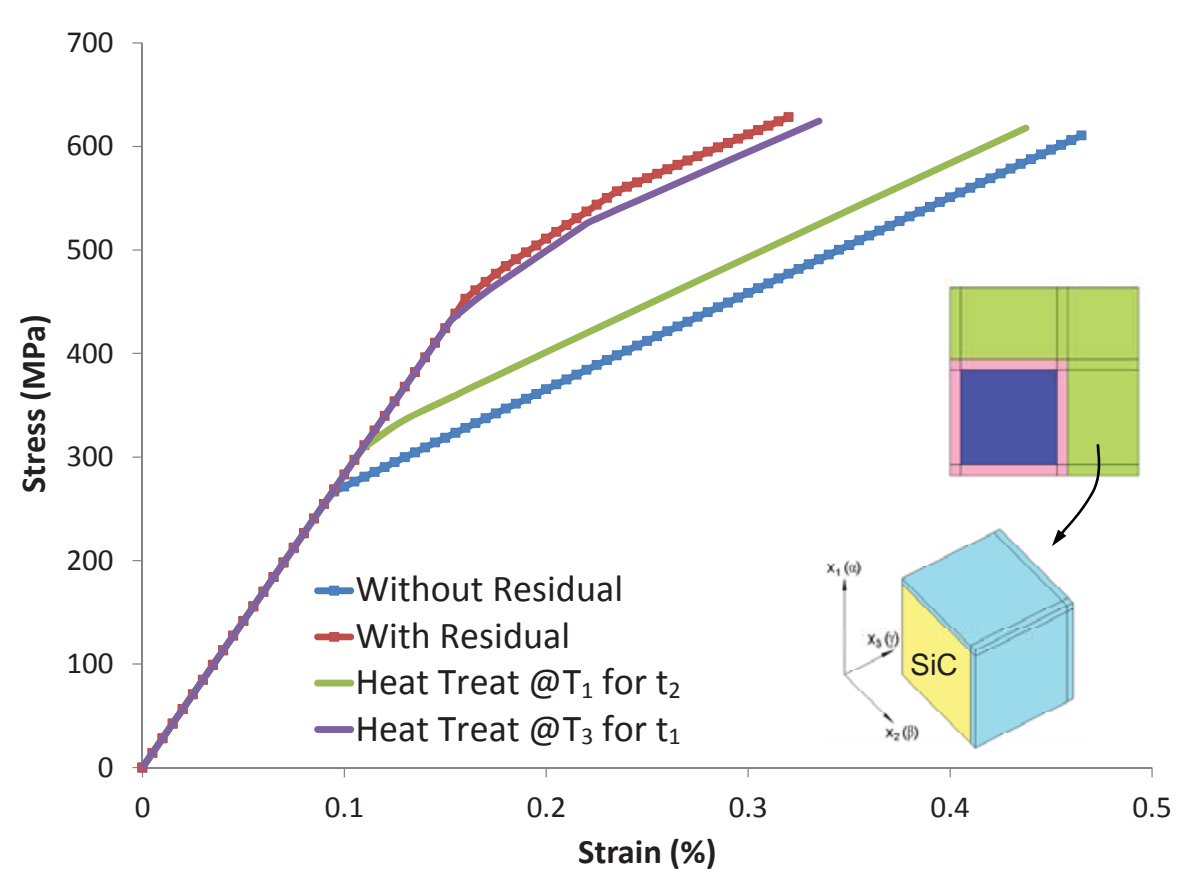

Figure 8. Predicted room temperature longitudinal tensile response of the unidirectional $\mathrm{MI} \mathrm{SiC} / \mathrm{SiC}$ composite after heat treatment at temperatures $T_{1}>T_{3}$ for times $t_{2}=t_{1} / 10$.

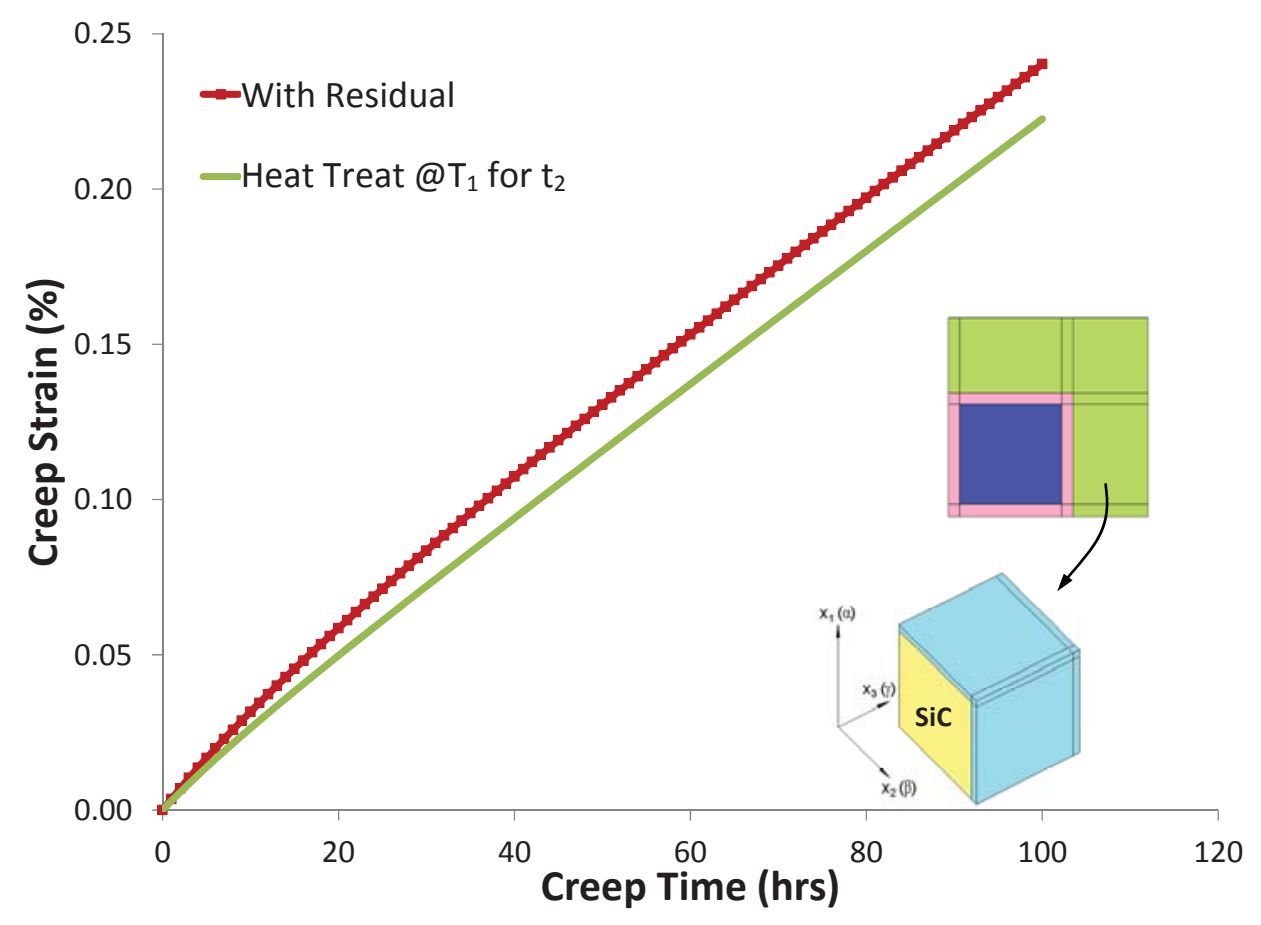

Figure 9. Predicted longitudinal creep response of the unidirectional $\mathrm{MI} \mathrm{SiC} / \mathrm{SiC}$ composite at temperature $\mathrm{T}_{1}$ with and without heat treatment, in response to an applied stress of $200 \mathrm{MPa}$. 


\section{Conclusion}

The MSGMC recursive micromechanics model has been applied to examine the effects of residual stresses in unidirectional MI SiC/SiC composites. By capturing the both the microstructure of the phases present within the matrix material and the microstructure of the fiber/matrix/coating system, the impact of the residual stresses on the

subsequent composite tensile response was illustrated. Key to these simulations was the inclusion of the creep behavior of the phases.

\section{References}

Aboudi, J., Arnold, S.M., and Bednarcyk, B.A. (2013) Micromechanics of Composite Materials: A Generalized Multiscale Analysis Approach, Elsevier, Oxford, UK.

Dunn, D.G. (2010) “The Effect of Fiber Volume Fraction in Hipercomp SiC-SiC Composites”, Ph.D. Thesis, Alfred University, Alfred, NY.

Liu, K.C., Chattopadhyay, A., Bednarcyk, B.A., Arnold, S.M. (2011) "Efficient Multiscale Modeling Framework For Triaxially Braided Composites using Generalized Method of Cells", Journal of Aerospace Engineering, Vol. 42, $162-170$.

Liu, K.C. and Arnold, S.M. (2013) "Statistical Influence of Scale Specific Features on the Progressive Damage of Woven Ceramic Matrix Composites (CMCs)", Computers, Materials and Continua, Vol. 35, 35-65.

Paley, M. and Aboudi, J. (1992) "Micromechanical Analysis of Composites by the Generalized Cells Model", Mechanics of Materials, Vol. 14, 127-139. 